\section{O aborto clandestino e a vulnerabilidade social no Brasil: desigualdade em saúde, direitos humanos e bioética de intervenção}

\author{
Nogueira, Larissa Takla de Biase \\ Mestranda em Direitos e Garantias Fundamentais pela \\ Faculdade de Direito de Vitória (FDV)*; Especialista em \\ Direito Tributário pelo Instituto Brasileiro de Direito \\ Tributário (IBET); Graduada em Direito pela Universidade \\ Federal do Espírito Santo (UFES); Advogada. e-mail: \\ larissadebiase@gmail.com
}

\section{Bussinguer, Elda Coelho de Azevedo}

Doutora em Bioética pela Universidade de Brasília (UnB); Livre-docente pela Universidade Federal do Estado do Rio de Janeiro (UniRio); Mestre em Direitos e Garantias Fundamentais pela Faculdade de Direito de Vitória (FDV); Coordenadora e professora do Programa de Pós-Graduação em Direitos e Garantias Fundamentais da Faculdade de Direito de Vitória (FDV); Coordenadora de Pesquisa da FDV*; Coordenadora do Grupo de Estudos, Pesquisa e Extensão em Políticas Públicas, Direito à saúde e Bioética (BIOGEPE); Professora associada aposentada da Universidade Federal do Espírito Santo (UFES).

PALAVRAS-CHAVE: Aborto, bioética interventiva, desigualdades da saúde, direitos das mulheres, determinantes sociais da saúde

A audiência pública do STF, ocorrida nos dias 3 e 6 de agosto de 2018, e transmitida ao vivo pelas maiores redes de televisão do país, desvelou uma realidade que se mantinha, até então, de certa forma, desconhecida, ou intencionalmente ignorada, pelo grande público, em razão dos conflitos morais que envolvem o tema: 1 em cada 5 mulheres já praticou o aborto e, dessas, metade necessitou de atendimento de serviços de saúde. Os dados do aborto clandestino no país e, em especial, o número de internações hospitalares, correntemente fatais, de mulheres em situação de vulnerabilidade foram trazidos à luz e apontam para um incontestável fato: a criminalização da prática abortiva não impede que estas mulheres continuem abortando. Além disso, a partir da análise do perfil predominante dessas mulheres (29\% são jovens, $22 \%$ possuem baixa escolaridade e $16 \%$ vivem com renda de até um salário mínimo), questiona-se se a penalização do cometimento do aborto clandestino, na prática, mantém a pobreza e um ciclo histórico de desigualdades. Diante dessa conjuntura, e reconhecendo-se a insuficiência teórica dos estudos bioéticos desenvolvidos nos países centrais, a pesquisa, por meio de uma abordagem dialética, intenciona repensar o tratamento legislativo do aborto a partir de uma perspectiva da bioética de intervenção latino-americana. Como foi investigado no decorrer do estudo, tal proposta epistemológica defende a intervenção direta do Estado na realidade social para proteção dos grupos desfavorecidos como forma de assegurar a estes os seus direitos fundamentais e a superação da desigualdade, de maneira desvencilhada de discursos religiosos fundamentalistas e absolutos morais. Constatou-se, assim, que o enfrentamento do problema persistente do aborto clandestino no país passa pelo reconhecimento dos determinantes sociais da saúde que aprisionam as mulheres vulneráveis nesses ciclos viciosos de exclusão social e desigualdades e as subjugam a um lugar de não-sujeitos de direitos, ainda que sobre os próprios corpos. Dessa forma, ao mesmo tempo em que estas mulheres são silenciadas nos processos de elaboração legislativa e nos debates midiáticos, o atual tratamento da prática abortiva culpabiliza a mulher em vulnerabilidade social e não considera a responsabilidade do Estado. Concluiu-se, portanto, pela necessidade de que o problema do aborto clandestino seja enfrentado como uma questão de saúde pública, com a necessária intervenção do Estado nessa realidade social. Pautando-se nessa concepção, foi demonstrado que o estabelecimento de políticas públicas preventivas e educacionais configuram medidas protetivas mais apropriadas no combate a essas desigualdades e no reconhecimento da mulher enquanto sujeito de direitos.

\section{REFERÊNCIAS}

[1] BUSSINGUER, Elda Coelho de Azevedo. A Teoria da Proporcionalidade de Robert Alexy: uma contribuição epistêmica para a construção de uma bioética latinoamericana. 229f. Tese (Doutorado em Bioética) Universidade de Brasília, Brasília, 2014.

[2] DINIZ, Debora; MEDEIROS, Marcelo; MADEIRO, Alberto. Pesquisa Nacional de Aborto 2016. Ciênc. saúde coletiva. Rio de Janeiro, v. 22, n. 2, p. 653-660, fev. 2017. [3] GARRAFA, Volnei. Da bioética de princípios a uma bioética interventiva. Revista bioética, v. 13, n. 1, 2009. p. 125-134.

[4] GARRAFA, Volnei; PORTO, Dora. Bioética, poder e injustiça: por uma ética de intervenção. In: GARRAFA, Volnei, PESSINI Leo. (orgs.). Bioética: poder e injustiça. 2 ed. São Paulo: Loyola, 2004. p. 35-44.

[5] OLIVEIRA, Aline Albuquerque S. de; VILLAPOUCA, Karin Calazans; BARROSO, Wilton. Perspectivas epistemológicas da bioética brasileira a partir da teoria de Thomas Kuhn. Revista brasileira de bioética. v. 1, n. 4, 2005. p. 363-385. 